\title{
Uma análise da Política Nacional de Saúde Integral LGBT à luz do conceito gramsciano de Estado ampliado
}

Analysis of the National Policy for LGBT Integral Health in Light of the Gramscian Concept of the Enlarged State

Une analyse de la Politique nationale de santé intégrale LGBT à la lumière du concept de Gramsci d'un État élargi

Dilermando Aparecido Borges Martins, Lislei Teresinha Preuss e Silmara Carneiro e Silva

\section{OpenEdition}

Journals

Edição electrónica

URL: https://journals.openedition.org/rccs/12438

DOI: $10.4000 /$ rccs. 12438

ISSN: 2182-7435

\section{Editora}

Centro de Estudos Sociais da Universidade de Coimbra

Edição impressa

Data de publição: 1 dezembro 2021

Paginação: 91-112

ISSN: 0254-1106

Refêrencia eletrónica

Dilermando Aparecido Borges Martins, Lislei Teresinha Preuss e Silmara Carneiro e Silva, «Uma análise da Política Nacional de Saúde Integral LGBT à luz do conceito gramsciano de Estado ampliado», Revista Crítica de Ciências Sociais [Online], 126 | 2021, publicado a 27 janeiro 2022, consultado a 29 janeiro 2022. URL: http://journals.openedition.org/rccs/12438; DOI: https://doi.org/ $10.4000 /$ rccs. 12438 


\section{DILERMANDO APARECIDO BORGES MARTINS, LISLEI TERESINHA PREUSS, SILMARA CARNEIRO E SILVA}

\section{Uma análise da Política Nacional de Saúde Integral LGBT à luz do conceito gramsciano de Estado ampliado}

Este artigo tem por objetivo refletir sobre a Política Nacional de Saúde Integral de Lésbicas, Gays, Bissexuais, Travestis e Transexuais (LGBT) no contexto das políticas públicas de saúde no Brasil e à luz da teoria do Estado ampliado de Antonio Gramsci, abrangendo as categorias Estado, Políticas Públicas e Saúde. Trata-se de uma pesquisa bibliográfica de caráter histórico e crítico. Para tanto, retrata-se o conceito gramsciano de Estado ampliado, aborda-se a Reforma Sanitária e, por fim, analisa-se a instituição da Política Nacional de Saúde Integral LGBT, especialmente a partir do conceito de vulnerabilidade no contexto das políticas públicas de saúde. Neste cenário, à luz da teoria gramsciana, depreende-se que a sociedade civil assume um papel importante na construção de políticas públicas para a população LGBT.

Palavras-chave: Brasil; Estado-nação; LGBT; políticas de saúde; vulnerabilidade social.

\section{Introdução}

A realidade e as demandas de Lésbicas, Gays, Bissexuais, Travestis e Transexuais $(\mathrm{LGBT})^{1}$ vêm sendo pautadas nas últimas décadas no cenário das políticas públicas no Brasil e, cada vez mais, alcança legitimidade, na medida em que esta comunidade se afirma na agenda pública como sujeito de direitos. Na luta pela sua afirmação social, cultural, política e de cidadania, esta comunidade vem resistindo, historicamente, ao padrão hegemônico de relações sociais vigentes no país. Este, alinhado à cultura judaico-cristã ocidental, impõe o padrão heterossexual e a negação das diversidades como referência relacional.

\footnotetext{
${ }^{1}$ Embora na atualidade a sigla utilizada seja LGBTQIA+, demonstrando a ampliação da proteção deste grupo, optou-se neste artigo por seguir a sigla adotada em 2008 na $1 .{ }^{a}$ Conferência Nacional GLBT, que adotou a sigla LGBT, assim como consta na Portaria do Ministério da Saúde analisada no presente estudo.
} 
Inscrita nesse contexto e resistindo ao padrão conservador e discriminatório das diferenças humanas, a comunidade LGBT vem alcançando importantes conquistas de cidadania no Brasil. Esta direção se dá a contrapelo das forças regressivas, conservadoras e reacionárias, que operam na correlação de forças e que impactam negativamente o conjunto de lutas que congrega suas pautas assim como as diferentes áreas das políticas sociais - como saúde, educação e habitação - devido às demandas públicas dos grupos vulneráveis historicamente negligenciados pelo Estado.

Considerando tais pressupostos, o presente trabalho tem por objetivo refletir sobre a Política Nacional de Saúde Integral LGBT no contexto das políticas públicas de saúde no Brasil e à luz da concepção de Estado ampliado de Antonio Gramsci. Trata-se de uma pesquisa bibliográfica de caráter histórico e crítico que intenta provocar a discussão sobre a garantia de direitos da comunidade LGBT, na perspectiva da sua afirmação, mediante um cenário de retrocesso no campo dos direitos e das políticas públicas, reforçado, ainda, com o retorno de discursos homofóbicos na cena pública brasileira.

O artigo está organizado em três itens. O primeiro apresenta uma reflexão sobre a concepção de Estado ampliado e outros elementos presentes na perspectiva gramsciana. Na sequência, apresenta-se uma reflexão sobre a Reforma Sanitária brasileira articulando-a com a leitura gramsciana. O terceiro e último item apresenta uma reflexão sobre a instituição da Política Nacional de Saúde Integral LGBT, objeto deste estudo, no qual se resgata a discussão da Reforma Sanitária brasileira, no contexto das políticas públicas de saúde, bem como o conceito de vulnerabilidade, considerando o direito à saúde conforme a Constituição Federal de 1988.

\section{A concepção de Estado em Gramsci}

Antonio Gramsci foi um marxista que colaborou na fundação do Partido Comunista Italiano. Durante o período em que ficou encarcerado, escreveu os "Cadernos do Cárcere", de onde foram extraídas suas principais ideias e pensamentos que contribuíram para os estudos das ciências sociais (Monasta, 2010).

Um dos importantes legados deixados pelo autor foi a sua concepção de Estado Integral, dito ampliado (Buci-Glucksmann, 1980). Gramsci considera a correlação de forças econômicas e políticas desde as primeiras décadas do século Xx. $\mathrm{O}$ autor reconhece, nesse período, a presença de aparatos hegemônicos na sociedade civil, os quais denomina de aparelhos privados de hegemonia. Gramsci ainda percebe que, nessa correlação de forças, parte das demandas das classes subalternas passa a ser incorporada 
pelo Estado Estrito (sociedade política). Nas palavras de Gramsci (2012: 248): “[...] na noção geral de Estado entram elementos que devem ser remetidos à noção de sociedade civil (no sentido, seria possível dizer, de que Estado = sociedade política + sociedade civil, isto é, hegemonia couraçada de coerção)".

Com isso, Gramsci (2012) identifica um deslocamento da base histórica do Estado, e esse deslocamento coloca o problema da hegemonia. Esta diz respeito à direção da sociedade num determinado contexto ou período histórico. Segundo Luciano Gruppi (2000: 1; itálicos no original):

O termo hegemonia deriva do grego eghestai, que significa "conduzir", "ser guia", "ser líder"; ou também do verbo eghemoneuo, que significa "ser guia", "preceder", "conduzir", e do qual deriva "estar à frente", "comandar", "ser o senhor".

A hegemonia não se refere simplesmente à subordinação de uma classe em relação a outra, mas compreende também a direção política e cultural, pensando em uma visão de mundo que deve ser incorporada pelas demais classes (Buci-Glucksmann, 1980). O conceito de hegemonia é fundamental para compreender a teoria gramsciana de Estado. Pensar no Estado ampliado de Gramsci significa reconhecer o exercício da hegemonia, que ocorre através do consenso das grandes massas em relação ao grupo dominante, somado ao aparelho de coerção estatal, que vai garantir legalmente que os grupos contrários ao estabelecido hegemonicamente sejam disciplinados. Há, então, uma batalha para que se formem acordos no interior da sociedade civil em seus diversos grupos sociais, através do próprio Estado ampliado, levando a uma direção ético-política através dos próprios mecanismos de consenso e hegemonia (Adams e Pfeifer, 2006). Para Carlos Nelson Coutinho (2012: 127; itálicos no original),

[...] o Estado em sentido amplo, "com novas determinações" comporta duas esferas principais: a sociedade política (que Gramsci também chama de "Estado em sentido estrito" ou de "Estado-coerção"), que é formada pelo conjunto dos mecanismos através dos quais a classe dominante detém o monopólio legal da repressão e da violência e que se identifica com os aparelhos de coerção sob controle das burocracias executiva e policial-militar; e a sociedade civil formada precisamente pelo conjunto das organizações responsáveis pela elaboração e/ou difusão das ideologias, compreendendo o sistema escolar, as Igrejas, os partidos políticos, os sindicatos, as organizações profissionais, a organização material da cultura (revistas, jornais, editoras, meios de comunicação de massa), etc. 
A sociedade política exerce seu poder por meio da dominação, através do Estado e de seu aparelho repressivo militar. Já a sociedade civil exerce seu poder por meio da direção política e do consenso, através dos aparelhos privados de hegemonia que são mais independentes e carregam a concretude da vida em sociedade e suas relações sociais (Simionatto, 1998). O processo de incorporação dos ditames dos grupos hegemônicos perpassa pela ideologia e pela cultura, em articulação com os processos de coerção, próprios da sociedade política. Envolve força e consenso, que são fundamentos do Estado (Bianchi e Aliaga, 2011).

Ao se constituir uma nova hegemonia, rompe-se com o campo da estrutura, que nada mais é do que um momento corporativo, puramente econômico, em que o ser humano é passional e contraído, para que se dirija à superestrutura, uma espécie de elaboração superior da estrutura, em que a sociedade pode se tornar meio de liberdade e criar uma nova forma ético-política. É neste momento que se atinge uma consciência universal e se abandonam os interesses corporativos e particulares, concretizando o ideário gramsciano do Estado ampliado (Simionatto, 1998).

Ressalta-se que o conceito de Estado em Gramsci está intrinsecamente relacionado à teoria da revolução que, na visão gramsciana, é histórica e processual. Ao atingir sua expressão universal, a revolução representará a superação do modo de produção capitalista. Para Gramsci o processo de transição se forma através de uma estratégia denominada "guerra de posição", ou seja, com a formação de consensos no interior da sociedade civil (Adams e Pfeifer, 2006). O que se nota é que o papel da sociedade civil, em Gramsci, é fundamental para que esta revolução ocorra e o Estado supere a sua dimensão egoísta-corporativa, assumindo-se ética e politicamente em favor da emancipação das classes populares.

A nova hegemonia - a socialista - une estes interesses individuais e os torna coletivos, numa ótica universal. Para tal, é preciso deixar para trás o egoísmo trazido pelos grupos corporativos da sociedade. Nesse sentido, Ivete Simionatto (1998: 46) afirma que:

Gramsci insiste na necessidade de que as classes sociais abandonem o seu modo de pensar corporativo, produto das relações sociais e do modo de ser próprio da sociedade burguesa, que obstaculiza a formação de um projeto coletivo. A construção da hegemonia exige, assim, compromissos de classe, superação de interesses particularistas e individuais, abertura de espaços para congregar as várias frações de classe. A partir da superação desse modo de ser e de pensar, a vontade coletiva avança e vai delineando uma nova consciência, que se manifesta e se concretiza na prática política. 
Neste caso, a formação de uma superestrutura de caráter ético-política vai se dar com a superação dos padrões burgueses de sociabilidade. Uma nova consciência e uma nova hegemonia dão forma a uma nova práxis política.

De acordo com Tarso Cabral Violin (2006), hodiernamente, o conflito social continua inscrito entre as classes, os grupos e em seus respectivos aparelhos privados de hegemonia, sendo a plena expressão da contradição entre capital e trabalho e também da trama política circunscrita na superestrutura. Nesta dimensão das disputas, os aparelhos privados de hegemonia, nos quais sobrevive o espírito de cisão, pulsam as pluralidades sociais, políticas e culturais. Para além da sociedade política, são espaços de luta pela hegemonia os movimentos sociais, as organizações não-governamentais, os sindicatos, as igrejas, os partidos, a imprensa, a escola.

Com esta breve exposição sobre o conceito de Estado ampliado em Gramsci, é possível estabelecer uma relação entre seus pressupostos teóricos e o contexto histórico de luta pela saúde pública brasileira - o movimento da Reforma Sanitária, expressão de uma luta que alçou conquistas junto à sociedade política, numa perspectiva não hegemônica. Este movimento é considerado um dos marcos importantes para a atual concepção de saúde sacralizada na Constituição Federal de 1988. A Reforma Sanitária contribuiu diretamente para traçar um desenho de luta por uma nova hegemonia no país. Muitas outras possibilidades se abririam a partir daí no universo das políticas públicas sociais brasileiras, que hoje servem de baliza para referenciar novas conquistas e/ou como escudos para barrar graves retrocessos - nomeadamente o rol de direitos sociais ameaçados pela Emenda Constitucional 95/2016, que estrangulou o financiamento das políticas públicas sociais na conjuntura recente do país (Costa, 2017). Somado a isso, tem-se ainda a agenda ultraconservadora do governo de Jair Bolsonaro (sem partido), que impõe sérios limites à efetivação de direitos.

\section{Reforma Sanitária brasileira: uma leitura gramsciana}

A Reforma Sanitária brasileira nasceu no início da década de 1970 e foi uma referência histórica fundamental para a atual concepção de saúde vigente no Estado brasileiro. Trata-se de um movimento que inclusive deu origem ao Sistema Único de Saúde (SUS), conforme preceituado na Constituição Federal de 1988 e em leis ordinárias, que tratam da temática (Brasil, 1998, 1990). A Reforma Sanitária foi um processo político e estratégico, com diversas articulações que permitiram uma mudança - ou um 
consenso - que reverberou no Estado Democrático de Direito brasileiro. Nas palavras de Sonia Fleury (2009: 746):

A reforma sanitária no Brasil é conhecida como o projeto e a trajetória de constituição e reformulação de um campo de saber, uma estratégia política e um processo de transformação institucional. Emergindo como parte da luta pela democracia, a reforma sanitária já ultrapassa três décadas, tendo alcançado a garantia constitucional do direito universal à saúde e a construção institucional do Sistema Único de Saúde (SUS).

Jaimilson Paim (2009) relembra que a saúde brasileira possuía campos distintos, englobando a saúde pública, com caráter preventivo e voltado para a coletividade; a saúde do trabalhador, que estava inserida no Ministério do Trabalho; além da medicina previdenciária e a assistência médica liberal e filantrópica. Ou seja, o que existia era uma estrutura fragmentária e dispersa que operava em favor da lógica mercantil, em detrimento da atenção em saúde dos grupos pauperizados.

Foi a partir de um sistema de crises na prática médica, no autoritarismo do Estado e na saúde da população como um todo que o movimento da Reforma Sanitária surgiu e se organizou, para que se construísse uma prática teórica voltada especialmente para a estrutura social (Fleury, 2009). É possível estabelecer uma relação entre os precursores deste movimento e alguns conceitos trazidos por Gramsci, posto que representou uma parcela da sociedade civil que na contramão da hegemonia buscou formular novos consensos, construir uma nova hegemonia. Ou seja, são os grupos que se unem e visam difundir uma ideologia, capaz de mudar a hegemonia existente. Segundo Guido Liguori (2017), em Gramsci, as ideologias se articulam com os aparelhos privados de hegemonia e têm destaque no contexto do Estado ampliado. Para Gramsci, a ideologia é uma concepção de mundo que se constrói determinada pelo contexto de vida em que se inserem os sujeitos.

Sob os auspícios da ideologia dominante, fundada em interesses que se inscreveram no então regime militar, o movimento da Reforma Sanitária, ao lado de outros movimentos não hegemônicos, lutou pela democratização da sociedade brasileira e, neste caso específico, abriu caminhos para a sacralização do direito à saúde no Estado, enquanto um direito de todos, indistintamente.

Para Maria Bravo e Maurílio Matos (2012), o projeto de Reforma Sanitária, que foi uma das principais conquistas do movimento, teve como preocupação central assegurar a atuação do Estado em função da sociedade, 
[...] pautando-se na concepção de Estado democrático e de direito, responsável pelas políticas sociais e, por conseguinte, pela saúde. Como fundamentos dessa concepção, destacam-se: melhor explicitação do interesse público, democratização do Estado, criação de uma esfera pública como controle social. Outros aspectos significativos da proposta são: democratização do acesso, universalização das ações, descentralização, melhoria da qualidade dos serviços com adoção de um novo modelo assistencial pautado na integralidade e equidade das ações. (Bravo e Matos, 2012: 202)

Com esta contextualização, nota-se a ideia gramsciana de Estado ampliado, na particularidade do Estado brasileiro, em que a disputa pela hegemonia por parte dos grupos organizados da sociedade civil, ao lado dos quais lutavam os sanitaristas, se dá do consenso de que a saúde se constituía um direito de todos, representativa de valores democráticos. Aqui a noção de vontade coletiva, associada ao projeto de Reforma Sanitária, vincula-se à trama social e política brasileira, à época, enquanto um elemento democrático. Vontade coletiva, na visão gramsciana, se constitui um elemento de democracia. Segundo Coutinho (1996: 27) "[...] a democracia implica a gestação de uma vontade geral. O que pressupõe um consenso - ou um contrato - tanto sobre conteúdos como sobre procedimentos".

A Reforma Sanitária é, portanto, uma estratégia política que conquista a possibilidade de empreender um processo de transformação institucional, incorporando na sociedade política parte das demandas advindas dos setores contra-hegemônicos da sociedade civil, através do consenso. Segundo Coutinho (2009), a vontade coletiva é traduzida pelo consenso em Gramsci.

As bases teóricas que fundamentaram a construção deste projeto da reforma sanitária podem ser encontradas na revisão da concepção marxista do Estado e na elaboração de uma leitura crítica do campo da saúde coletiva.

A concepção do marxismo contemporâneo sobre o Estado tem início com a ruptura que a obra de Gramsci introduz; ao compreender o Estado, para além de suas funções repressivas de tutela de uma sociedade de classes, como exercendo um papel fundamental em sua função pedagógica de construção, consolidação e reprodução da direção cultural da classe hegemônica. (Fleury, 2009: 746)

A busca do consenso para uma nova concepção de saúde foi representada por vários segmentos da sociedade civil, peça fundamental na teoria de Gramsci. De acordo com Sarah Escorel (2008), identificam-se três grupos que compunham o movimento da Reforma Sanitária: em primeiro lugar, 
os estudantes inseridos no movimento estudantil e o Centro Brasileiro de Estudos de Saúde que lutavam contra a privatização da saúde e a favor de uma implementação democrática, voltada especialmente para o lado social e de consciência sanitária; em segundo lugar, os movimentos de Médicos Residentes e de Renovação Médica, atuantes no campo de trabalho para uma mudança concreta; por fim, os docentes e pesquisadores, trabalhando diretamente em uma teoria a ser difundida por todos os meios sociais.

Aqui, em especial, vale destacar o papel dos intelectuais no processo de articulação da nova ideologia e na capacidade organizativa em torno da impressão das mudanças institucionais, no âmbito do Estado ampliado. O papel do intelectual "orgânico", na visão gramsciana, é de organizador da cultura, o que significa ser o agente da transformação, articulando-se à trama estrutural e superestrutural. $\mathrm{O}$ referido intelectual, portanto, é sujeito imprescindível para a construção de uma nova hegemonia (Santos, 2009).

Pode-se dizer que os segmentos da sociedade civil articulados em torno da Reforma Sanitária deram origem a uma nova concepção de saúde, baseada em um consenso em favor de uma nova direção política neste campo. Há ainda inclusive a presença da sociedade política, conforme definida por Gramsci, quando grupos pertencentes ao próprio aparelho estatal começam a participar do movimento da Reforma Sanitária (Kleba, 2005).

$\mathrm{Na}$ visão gramsciana a busca de uma nova direção política e de uma hegemonia baseada no consenso é um processo moroso, a transformação não ocorrendo de uma hora para outra. Com a Reforma Sanitária não foi diferente, posto que a proposta gerava mudanças nos padrões estabelecidos e na hegemonia vigente, e conquanto não alterava substancialmente o padrão das relações de forças sociais, ainda assim verificava-se a incorporação parcial das demandas sob o controle da institucionalidade - ou seja, da sociedade política. Escorel (2008) relembra que a resistência no ideário transformista da Reforma era grande e que o processo de mudança não foi simples, principalmente por conta da resistência dos setores privatizantes de saúde.

$\mathrm{Na}$ evolução cronológica da Reforma destacam-se alguns eventos importantes frutos desta articulação da sociedade civil e da sociedade política. No ano de 1979, ocorreu o I Simpósio de Política Nacional de Saúde da Câmara dos Deputados, durante o qual foi possível estabelecer um diálogo e ceder um espaço para que se expusessem alguns pontos fundamentais para a nova concepção de saúde. Em 1980 realizou-se a 7. ${ }^{a}$ Conferência Nacional de Saúde, cujo escopo principal foi a articulação 
entre o Ministério da Previdência, da Saúde e da Assistência Social para trabalhar em prol da saúde enquanto direito de todos. Em 1981, a recessão econômica provocou uma crise na previdência, atingindo a assistência médica previdenciária, dando forças à discussão em torno da saúde descentralizada. Surge, neste período, as Ações Integradas de Saúde voltadas para o setor público e com o propósito de democratização e descentralização da saúde, propondo um sistema unificado (Escorel, 2008). O ano de 1986 foi marcante para o movimento da Reforma Sanitária, posto que na 8. ${ }^{a}$ Conferência Nacional de Saúde foram debatidas as propostas da sociedade civil, em especial a criação de um sistema único de saúde, integral e universal, que pudesse mudar definitivamente o cenário brasileiro (Paim, 2009). A Reforma Sanitária, como proposta resultante de um movimento da sociedade civil foi consolidada com o fim do regime ditatorial e início da democratização, através da Constituição Federal de 1988 e com a promulgação das leis orgânicas de saúde, nomeadamente as leis n. ${ }^{\circ} 8.080 / 90$ e n. $^{\circ} 8.142 / 90$ (Brasil, 1990).

Como afirmado por Paim (2008), o movimento é considerado um dos principais atores sociais no processo de concepção e implementação do SUS e do direito universal à saúde. O SUS foi articulado pela sociedade civil brasileira, que lutou por um novo consenso em termos de saúde, cuja conquista foi efetivada e contribuiu para importantes avanços na garantia do direito à saúde e na ampliação de seu conceito - o que em termos gramscianos representou, por um lado, um avanço dos grupos subalternos na luta pela hegemonia e, por outro, a cooptação das demandas do movimento da Reforma Sanitária pelo Estado capitalista.

A sacralização da saúde enquanto um direito constitucional universal não assegurou a sua real efetivação na realidade brasileira pós-1988. A década de 1980 foi de avanços jurídico-políticos, porém a década de 1990 foi de retrocessos econômicos. A adoção do modelo neoliberal impôs restrições à materialização dos chamados direitos sociais no país. Assim, embora o direito à saúde tenha sido assegurado constitucionalmente, essa garantia não foi suficiente para romper com a lógica de precarização dos direitos determinada pela conjuntura de arrocho econômico. A lógica de mercantilização dos direitos, somada ao ultraconservadorismo que assola o Brasil em conjuntura recente, têm impactos importantes na direção de retrocessos no campo das políticas públicas, de entre as quais para a política de saúde integral LGBT - objeto de análise no presente artigo. 


\section{A instituição da Política Nacional de Saúde Integral LGBT no Estado ampliado}

A Reforma Sanitária brasileira permitiu que parte das demandas do movimento fosse incorporada no Estado "de baixo para cima", em termos de saúde. Compreendido como um movimento social, conseguiu agregar diferentes grupos de interesse, com distintas origens sociais, gêneros e etnias em torno de um projeto comum agregando: o direito à saúde, um sistema único de saúde e a democracia. Como se evidenciou, do esforço pela redução da desigualdade social resultou o SUS (Campos, 2018).

Destaca-se, nesse sentido, a afirmação de uma concepção ampliada do atendimento em saúde, baseada na noção de integralidade, equidade e universalidade. O processo de redemocratização da saúde, a partir do caráter contra-hegemônico da Reforma Sanitária brasileira, propiciou abertura para o debate sobre cidadania e direitos sociais, repercutindo-se em importantes contribuições para a construção de um modelo de assistência pautado na equidade em saúde, incluindo as populações até então marginalizadas (Bezerra et al., 2019).

Das principais características do movimento, o ativismo político e profissional, a busca por mudanças em todos os níveis do sistema e a produção teórica, metodológica e estratégias de intervenção de acordo com as diretrizes e princípios do SUS são as mais inovadoras (Campos, 2018). Os ativistas do direito à saúde integravam-se em diferentes movimentos, sendo um deles o LGBT. Neste contexto, ao pensar a saúde como um processo que envolve questões biológicas, sociais e psicológicas e ao defender a adoção de uma nova concepção de saúde, o movimento da Reforma Sanitária pauta a incorporação das demandas do movimento LGBT. Nessa noção ampliada de saúde são defendidas ações de promoção, prevenção e recuperação, com uma qualidade de vida garantida a todos indistintamente, considerando o desenvolvimento humano em sua individualidade.

Seus pilares assentados no caráter universal, integral, equitativo e descentralizado, se explicitam no artigo 198 da Constituição Federal de 1988, que assim dispõe:

Art. 198: As ações e serviços públicos de saúde integram uma rede regionalizada e hierarquizada e constituem um sistema único, organizado de acordo com as seguintes diretrizes: I - descentralização, com direção única em cada esfera de governo; II - atendimento integral, com prioridade para as atividades preventivas, sem prejuízo dos serviços assistenciais; III - participação da comunidade (Brasil, 1988). 
Este novo sistema de saúde permite que sejam abordadas algumas políticas voltadas para grupos em situação de vulnerabilidade, como é o caso da comunidade LGBT. Pois pensar em integralidade significa levar em consideração os diversos determinantes que podem afetar a saúde (Brasil, 1990).

É no final da década de 1970 que a população LGBT passou a ter visibilidade no cenário brasileiro, a partir de movimentos sociais em defesa de seus direitos civis, políticos, sociais. Esta população travou lutas objetivando romper com preconceitos, estereótipos e diferentes formas de violência. Bezerra et al. (2019: 314) afirmam que "[...] a trajetória do movimento LGBT obteve maior ascensão social a partir da redemocratização brasileira”. É nesse período que os governos foram mais favoráveis e de maior abertura às demandas da comunidade LGBT, que conquistou avanços nas políticas públicas implementadas nas diversas áreas sociais, especialmente na saúde (Bezerra et al., 2019). É nesta área que, na década de 1980, se iniciam as lutas contra o vírus HIV e se desenvolvem ações de prevenção das Doenças Sexualmente Transmissíveis (hoje denominadas IST - Infecções Sexualmente Transmissíveis), nos cenários nacional e internacional (Brasil, 2013). Já na década de 1990, o número de grupos organizados relacionados a esta população se amplia, articulando-se e dando maior ênfase na diversidade sexual como algo inerente às questões políticas e sociais. A visibilidade neste período pode ser exemplificada pela Parada do Orgulho LGBT realizada em São Paulo (Bezerra et al., 2019).

Neste cenário, as diversas organizações representativas da comunidade LGBT deram visibilidade às dificuldades que este grupo vivia, articulando-se em busca da implementação de direitos, em uma proximidade da ideia gramsciana de participação social na busca de um consenso. De entre estes grupos, destacam-se o Grupo Gay da Bahia, a Associação Brasileira de Lésbicas, Gays, Bissexuais, Travestis e Transexuais (ABGLT), a Associação Nacional de Travestis e Transexuais (Antra) e o Grupo Dignidade, do Paraná.

Compreendendo a questão saúde como objeto de ação política, diversos movimentos sociais organizados apresentaram demandas e especificidades aos governantes tendo em vista que, embora a RSB [Reforma Sanitária Brasileira] tenha propiciado a permeabilidade para as demandas das minorias sociais, tais diálogos obtiveram uma penetração heterogênea no âmbito governamental. Esse fato corroborou o desenvolvimento tardio de políticas públicas de saúde, como observado para população LGBT, impulsionadas somente a partir de 2004 com a publicação do Plano Brasil Sem Homofobia. (Bezerra et al., 2019: 306) 
Partindo do contexto histórico de luta por direitos LGBT, alguns marcos tornam-se relevantes na determinação da política atual, objeto do presente trabalho. Em 2004, a Secretaria Especial de Direitos Humanos da Presidência da República, com a participação da sociedade civil, elaborou o Brasil Sem Homofobia - Programa de Combate à Violência e à Discriminação contra GLTB e de Promoção da Cidadania Homossexual, instituído nesse mesmo ano pelo Governo e cujo objetivo era criar programas contrários à discriminação e que promovessem equidade no acesso a serviços públicos, inclusive o da saúde (Brasil, 2013).

Cabe ressaltar que em 2006 a comunidade LGBT conseguiu representação no Conselho Nacional de Saúde. Esta conquista representou um marco para a luta LGBT no Brasil, pois significou a participação efetiva desta parcela da sociedade na institucionalidade pública, o que conferiu um novo sentido à atuação do movimento pela democratização no SUS (Brasil, 2013). No sentido gramsciano, demarca a incorporação da comunidade LGBT no interior do Estado.

Em 2007 realizou-se a $13 .{ }^{a}$ Conferência Nacional de Saúde, em que algumas demandas da comunidade LGBT foram levadas em consideração. Em 2008, decorreu a I Conferência Nacional de LGBT, tendo o Ministério da Saúde ficado responsável pela elaboração dos princípios de uma política de saúde LGBT. Em 2009, esta foi aprovada pelo Conselho Nacional de Saúde e posteriormente legitimada pela Portaria n. ${ }^{\circ} 2.836$ de $1 .^{\circ}$ de dezembro de 2011. De acordo com esta política, as questões de saúde que envolvem os grupos LGBT são complexas. Ressalta-se, assim, a prostituição como espaço para exercer a sua feminilidade (rejeitada em outros espaços sociais) e também o uso de drogas, silicone industrial, hormônios e outros medicamentos sem atenção médica. Estas ações são propensas ao aumento dos riscos de se contrair IST, além de elevarem a violência, o que afeta diretamente a saúde das pessoas envolvidas (Brasil, 2013).

São colocados como pontos importantes para justificar a atenção à saúde de LGBT os problemas de depressão, crises de ansiedade e sensação de pânico entre travestis e transexuais, afetando sua saúde mental e levando, inclusive, ao suicídio. A violência sofrida em relação ao desrespeito pelo uso do nome social também é fator primordial, o que é prejudicial à saúde daqueles que diretamente sofrem com isto (ibidem).

Alguns dados estatísticos servem de base para justificar o porquê da política LGBT, posto que reforçam os argumentos trazidos por seus idealizadores. Um estudo elaborado pela Rede Feminista de Saúde no ano de 2006 relata que $40 \%$ das mulheres que procuram por assistência à saúde 
não assumem sua orientação sexual por conta do preconceito. Entre as que revelam sua orientação, $28 \%$ afirmam maior rapidez no atendimento e 17\% relatam a ausência de solicitação de exames por elas considerados necessários. Destaca-se um estudo do Ministério da Saúde, de 2008, acerca da maior vulnerabilidade ao vírus HIV entre gays e bissexuais masculinos, motivados pela homofobia e segregação. O $3 .^{\circ}$ Relatório Nacional sobre os Direitos Humanos no Brasil aponta para 360 homicídios de gays, lésbicas e travestis entre os anos de 2003 e 2005 (Brasil, 2013).

O Atlas da Violência de 2021 fez uma análise a partir de dados referente à produção do serviço de denúncias e proteção contra violências Disque Direitos Humanos - Disque 100, vinculado ao Ministério da Mulher, da Família e dos Direitos Humanos, e de dados produzidos pelo Sistema de Informação de Agravos de Notificação (Sinan) do Ministério da Saúde. Em relação ao Disque 100, no período compreendido entre 2011 e 2019, o sistema registrou em média 1666 denúncias anuais de violências contra pessoas LGBTQI+. Na análise da série histórica destaca-se o ano de 2012, quando o sistema registrou 3031 denúncias, e o ano de 2019, que apresentou redução expressiva e fechou com apenas 833 denúncias, uma redução de $50 \%$ em relação ao ano anterior (Cerqueira et al., 2021).

No que se refere aos números de notificações de violências registrados pelo Sinan entre os anos de 2018 e 2019, verifica-se um crescimento de $5 \%$ nas violências contra homossexuais e $37,1 \%$ nas violências contra bissexuais. A maior parte dos registros de violências por orientação sexual é de pessoas assumidamente homossexuais, perfazendo $81,8 \%$ do total de notificações no último ano (ibidem). Entre a população trans verifica-se o aumento do valor bruto das notificações de violência física em 5,6\%, e da psicológica em 13,5\%. As notificações de tortura reduziram 3,4\%, mas os outros tipos de violência aumentaram em 30\% (ibidem).

Considera-se, nesse sentido, a noção de processo saúde-doença relacionada com a questão do bem-estar. A partir desta concepção, não se abordam apenas as ações individuais - como as preventivas, vacinações, educação em saúde -, mas também as ações coletivas, voltadas para diversos fatores que influenciam a própria saúde, como as condições sociais, a renda e o status social. Conforme Lucila Vianna (2005: 4), "[...] o processo saúde-doença representa o conjunto de relações e variáveis que produzem e condicionam o estado de saúde e doença de uma população, que variam em diversos momentos históricos e do desenvolvimento científico da humanidade”. A política de saúde LGBT se pauta, na perspectiva apresentada por Vianna (2005), justamente por considerar a determinação social como um elemento central no processo saúde-doença. 
Esta tem em conta que a exclusão social é responsável por interferir em diferentes aspectos da vida do sujeito, como a falta de acesso à habitação, alimentação, cultura, lazer, educação e saúde - sendo todas elas formas de discriminação (Brasil, 2013).

A vulnerabilidade social é uma realidade que atinge a população LGBT e que determina as suas condições de saúde. De acordo com José Ayres et al. (2006), a vulnerabilidade social contempla a existência de outros fatores para além da dimensão individual, nomeadamente as questões culturais, materiais, políticas e morais. Assim, toma-se por base "[...] a estrutura jurídico-política e as diretrizes governamentais dos países, as relações de gênero, as relações raciais, as relações entre gerações, as atitudes diante da sexualidade, as crenças religiosas, a pobreza, etc." (ibidem: 397). A vulnerabilidade socialmente determinada expõe os sujeitos a ações estigmatizadoras que incorrem em diversos tipos de violência. No caso da população LGBT, destaca-se o desrespeito do uso do nome social, o preconceito, a heteronormatividade em relação às mulheres lésbicas, a falta de aceitação social e a violência em si, seja física ou psicológica.

A vulnerabilidade social, a discriminação, o preconceito e a violência

[...] demonstram a complexa cadeia relacional entre estigma e adoecimento que, por sua vez, culmina no afastamento do público LGBT do cuidado em saúde, e a necessidade da articulação de ações voltadas para promoção de ações diferenciadas, com o objetivo de reduzir desigualdades de grupos em condições de exclusão social e iniquidade em saúde, mesmo quando este é disponibilizado no SUS. (Bezerra, 2019: 317)

Resultante deste processo histórico de lutas pela inclusão desta parcela de grupos excluídos historicamente, instaurou-se no âmbito do SUS, em 2011, uma política pública LGBT. A Política Nacional de Saúde Integral LGBT foi instituída pela Portaria n. ${ }^{\circ} 2.836$, de $1 .^{\circ}$ de dezembro de 2011, através do Ministério da Saúde.

A Política Nacional de Saúde LGBT é um divisor de águas para as políticas públicas de saúde no Brasil e um marco histórico de reconhecimento das demandas desta população em condição de vulnerabilidade. É também um documento norteador e legitimador das suas necessidades e especificidades, em conformidade aos postulados de equidade previstos na Constituição Federal e na Carta dos Usuários do Sistema Único de Saúde. (Brasil, 2013: 6) 
Em seu processo de implantação são desenvolvidas "[...] ações para evitar a discriminação contra lésbicas, gays, bissexuais, travestis e transexuais nos espaços e no atendimento dos serviços públicos de saúde" (Brasil, 2013: 6). Tais ações representam o reconhecimento das diversidades humanas no âmbito do Estado e ainda que a pauta da população LGBT, historicamente excluída no Brasil, passou a ser considerada na formulação de políticas públicas. Destaca-se, neste caso, que a elevação da consciência desta parte da sociedade civil impactou a política de saúde a nível nacional; que o compromisso assumido pelo Estado ao instituir a Política Nacional de Saúde Integral LGBT foi significativo - ética e politicamente - contribuindo no processo de elevação intelectual e moral da sociedade brasileira. No entanto, esta mesma sociedade, em contextos regressivos como o atual e dada a sua pluralidade, passa a se comportar hegemonicamente contrária a direções progressistas - como a apontada pelos avanços da conquista de direitos da comunidade LGBT. Por isso, é necessário, em tempos de retrocesso, reafirmar o disposto na legislação para que sejam lembrados os preceitos constitucionais e as demais conquistas deles derivadas. E esse é também o compromisso deste artigo ao tratar da Política Nacional de Saúde Integral LGBT.

Esta foi estruturada em oito artigos, que explicam de que modo funciona, e tem como objetivo geral promover a saúde integral da população LGBT, a fim de eliminar a discriminação e o preconceito institucional para reduzir desigualdades e transformar o SUS em um sistema universal, integral e equitativo, conforme preceitua seu artigo $1 .^{\circ}$.

Ao propor uma política que visa eliminar discriminação e preconceito institucional para reduzir desigualdades, o Estado toma uma posição político-institucional diante da questão. De problema social, as demandas da comunidade LGBT passaram a ser reconhecidas pelo Estado como pautas legítimas para as políticas públicas - neste caso, para a política de saúde. Nesta perspectiva, um conjunto de ações passou a pautar a institucionalidade pública, o que se tornou explícito nos objetivos específicos da respectiva Política. Dos 23 incisos de seu artigo 2. ${ }^{\circ}$, que se referem aos seus objetivos específicos, destacam-se os seguintes: ampliar o acesso da população LGBT aos serviços de atendimento do SUS (II); qualificar a rede de atendimento do SUS para dar melhor atenção à população LGBT (III); criar estratégias para diminuir a mortalidade de travestis (IX); proporcionar cuidado à saúde de adolescentes e idosos LGBT (X); oferecer atenção integral às IST no âmbito do SUS (XI); eliminar os preconceitos nos serviços de saúde (XVI); garantir o uso do nome social aos usuários do SUS (XVII) (Brasil, 2013: 20-22). Em seu artigo 3. ${ }^{\circ}$ a Portaria n. ${ }^{\circ} 2.836$ 
vai elencar as diretrizes que norteiam a execução da Política. Destas, destacam-se o respeito aos direitos humanos, a promoção da cidadania, a eliminação das homofobias, o acesso à informação, além da produção de conhecimento científico - o que é possibilitado, inclusive, na produção deste trabalho (Brasil, 2013).

Os artigos $4 .^{\circ}, 5 .^{\circ}$ e $6 .^{\circ}$ definem, respectivamente, as competências da União - através do Ministério da Saúde -, dos Estados e dos Municípios brasileiros $^{2}$ para que esta política seja implementada, que vão desde ações voltadas para a divulgação, a promoção e o monitoramento até às práticas educativas e aos profissionais de saúde.

Além dos artigos estruturados na referida portaria, são apresentadas justificativas à criação desta política. Há que ressaltar, primeiramente, que a mesma é fruto da luta de movimentos sociais organizados, que fizeram frente ao Estado para que fosse dada uma atenção especial a este grupo. É ainda fruto da concepção ampliada de saúde - existente graças a Reforma Sanitária brasileira e da ideia de Estado Democrático de Direito -, manifesta na Constituição Federal de 1988, que garante direitos fundamentais a todos indistintamente, entre os quais o direito à saúde (Brasil, 2013).

Neste âmbito se compreende que a instituição da Política Nacional de Saúde Integral LGBT não emergiu pelos interesses da sociedade política brasileira, mas sim "de baixo para cima", através de setores organizados da sociedade civil, de movimentos vinculados às demandas da população LGBT, historicamente excluída no Brasil. Tais demandas, uma vez institucionalizadas na sociedade política, obrigou-a a ampliar seus compromissos e ações, evidenciando a correlação de forças que compõe a trama do Estado ampliado.

\section{Conclusão}

Pode-se constatar que a Política Nacional de Saúde Integral LGBT está diretamente conectada com as demandas da sociedade civil incorporadas pelo Estado ampliado brasileiro, e que são frutos da intensa luta por direitos empreendida pela população LGBT.

Ao pensar na Reforma Sanitária brasileira, um dos pilares da política por trazer uma concepção ampla de saúde - que envolve especialmente a integralidade -, estabelece-se uma relação clara com a teoria de Gramsci acerca do Estado. O movimento da Reforma Sanitária foi representativo das forças não hegemônicas presentes na sociedade civil brasileira,

\footnotetext{
${ }^{2}$ No Brasil o Estado é federativo, composto pelos seguintes níveis de administração: União, Estados e Municípios.
} 
conforme explicitado pela teoria ampliada do Estado. Houve, assim, na disputa pela hegemonia a afirmação de uma direção política e cultural capaz de institucionalizar parte das demandas do grupo no Estado. Neste processo, alguns consensos foram concretizados a respeito do ideário de saúde, que foi materializado no âmbito da sociedade política, com a afirmação do direito à saúde na Constituição Federal de 1988, com a revisão do conceito de saúde, incorporando um conceito ampliado de saúde como referência.

Foi através da Reforma Sanitária que se criou o SUS, cujos pilares universalidade, integralidade e equidade é que permitiram a criação de uma política voltada para a comunidade LGBT. Esta particularidade do Estado brasileiro está diretamente ligada aos ideais gramscianos de ampliação do Estado, na medida em que representou a incorporação das demandas de grupos não hegemônicos no âmbito da sociedade política, que no caso da comunidade LGBT ensejou na criação de política pública específica para a garantia do direito à saúde, considerando as diversidades humanas.

A própria participação de movimentos sociais engajados na luta por direitos da comunidade LGBT demonstram que a participação da sociedade civil é fundamental para que haja uma direção política mais aberta ao novo, ampliando no Estado elementos de defesa dos interesses de grupos não hegemônicos da sociedade civil.

Conforme demonstrado, os problemas da saúde para a comunidade LGBT são inúmeros, comprovados por pesquisas quantiqualitativas, que trazem à tona a necessidade de uma atenção para esta população com políticas efetivas e que possam garantir dignidade, conforme estabelecido pelos direitos fundamentais da República.

Por fim, o que se pretendeu no presente trabalho foi realizar uma reflexão acerca da articulação entre a teoria gramsciana, quanto à sua concepção de Estado e à particularidade do Estado brasileiro no que tange à saúde - através da Reforma Sanitária como um movimento de participação da sociedade civil e da concepção ampliada de saúde -, e a formulação de política pública para a comunidade LGBT nesta temática. Ressalta-se que não houve nenhuma pretensão de se esgotar tal temática, posto que é possível fazer uma análise sobre a ótica de outros teóricos acerca do Estado, ampliando ainda mais o debate para as ciências sociais.

Revisto por Ana Sofia Veloso 


\section{Referências bibliográficas}

Adams, José Rodrigo Barth; Pfeifer, Mariana (2006), "O Estado ampliado de Gramsci”, Revista Mosaico Social, 3, 239-248.

Ayres, José Ricardo de Carvalho Mesquita; Calazans, Gabriela Junqueira; Saletti Filho, Heraldo César; Franca Junior, Ivan (2006), "Risco, vulnerabilidade e práticas de prevenção e promoção da saúde”, in Gastão Wagner de Souza Campos; Maria Cecília de Souza Minayo; Marco Akerman; Marcos Drumond Júnior; Yara Maria de Carvalho (orgs.), Tratado de saúde coletiva. São Paulo/Rio de Janeiro: Hucitec/ /Editora Fiocruz, 375-417.

Bianchi, Alvaro; Aliaga, Luciana (2011), "Força e consenso como fundamentos do Estado: Pareto e Gramsci”, Revista Brasileira de Ciência Política, 5, 17-36. Consultado a 28.03.2020, em http://www.scielo.br/scielo.php?script=sci_arttex t\&pid=S0103-33522011000100002.

Bezerra, Marcos Vinicius da Rocha; Moreno, Camila Amaral; Prado, Nília Maria de Brito Lima; Santos, Adriano Maia dos (2019), "Política de saúde LGBT e sua invisibilidade nas publicações em saúde coletiva”, Saúde em Debate, 43(spe. 8), 305-323. Consultado a 13.09.2020, em https://www.scielo.br/j/sdeb/a/DkZJz3V 4kfLczm7Qbvpr3Xh/?lang=pt.

Brasil (1988), Constituição da República Federativa do Brasil. Brasília: Senado.

Brasil (1990), Lei n. 8.080 de 19 de setembro de 1990 - Dispõe sobre as condições para a promoção, proteção e recuperação da saúde, a organização e o funcionamento dos serviços correspondentes e dá outras providências. Presidência da República, Brasília. Consultado a 12.09.2021, em http://www.planalto.gov.br/ccivil_03/leis/L8080.htm.

Brasil (2013), Política Nacional de Saúde Integral de Lésbicas, Gays, Bissexuais, Travestis e Transexuais. Brasília: Ministério da Saúde [1. a ed.].

Bravo, Maria Inês Souza; Matos, Maurílio Castro de (2012), "A saúde no Brasil: reforma sanitária e ofensiva neoliberal”, in Maria Inês Souza Bravo; Potyara Amazoneida Pereira (orgs.), Política social e democracia. São Paulo/Rio de Janeiro: Cortez/Editora da UERJ, 200-220 [5. a ed.].

Buci-Glucksmann, Christine (1980), Gramsci e o Estado. Rio de Janeiro: Paz e Terra. Tradução de Angelina Peralva.

Campos, Gastão Wagner de Sousa (2018), “SUS: o que e como fazer?”, Ciência \& Saúde Coletiva, 23(6), 1707-1714. Consultado a 12.09.2021, em https://www.scielo. $\mathrm{br} / \mathrm{j} / \mathrm{csc} / \mathrm{a} / Z \mathrm{PyBXcTXwZvLh5H9PDzvxpn/?lang=pt.}$

Cerqueira, Daniel; Ferreira, Helder; Bueno, Samira (coords.) (2021), Atlas da violência 2021. São Paulo: Ipea/FBSP/IJSN. Consultado a 12.09.2021, em https://www.ipea. gov.br/atlasviolencia/arquivos/artigos/1375-atlasdaviolencia2021 completo.pdf.

Costa, Lúcia Cortes (2017), “A seguridade social sob a ameaça do ajuste recessivo no Brasil”, Emancipação, 17(1), 9-21. Consultado a 07.09.2021, em https://revistas. uepg.br/index.php/emancipacao/article/view/10412. 
Coutinho, Carlos Nelson (1996), "Crítica e utopia em Rousseau”, Revista Lua Nova, 38, 5-30. Consultado a 13.09.2021, em https://www.scielo.br/j/ln/a/pCDtnnCQ $5 \mathrm{kCbbXRkL} 83 \operatorname{Tn} 4 \mathrm{~L} /$ ?format=pdf\&lang=pt.

Coutinho, Carlos Nelson (2009), “O conceito de vontade coletiva em Gramsci”, Revista Katálisys, 12(1), 32-40. Tradução de Anna Palma. Consultado a 06.09.2021, em https://periodicos.ufsc.br/index.php/katalysis/article/view/S1414-49802009 000100005.

Coutinho, Carlos Nelson (2012), Gramsci: um estudo sobre seu pensamento político.

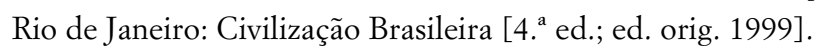

Escorel, Sarah (2008), "História das políticas de saúde no Brasil de 1964 a 1990: do golpe militar à Reforma Sanitária”, in Ligia Giovanella; Sarah Escorel; Lenaura de Vasconcelos Costa Lobato; José Carvalho de Noronha; Antonio Ivo de Carvalho (orgs.), Politicas e sistema de saúde no Brasil. Rio de Janeiro: Editora Fiocruz, 385-434.

Fleury, Sonia (2009), "Reforma sanitária brasileira: dilemas entre o instituinte e o instituído", Ciência \& Saúde Coletiva, 14(3), 743-752. Consultado a 29.06.2021, em http://www. scielo.br/scielo.php?script=sci_arttext $\&$ pid $=$ S1413-81232009000300010\&lng $=$ pt \&nrm=iso.

Gramsci, Antonio (2012), Cadernos do cárcere - Volume 3. Maquiavel: notas sobre o Estado e a política. Rio de Janeiro: Civilização Brasileira. Edição e tradução de Carlos Nelson Coutinho [5. a ed.; ed. orig. 1999].

Gruppi, Luciano (2000), O conceito de hegemonia em Gramsci. Rio de Janeiro: Edições Graal. Tradução de Carlos Nelson Coutinho [4. ${ }^{\text {a }}$ ed.; ed. orig. 1978].

Kleba, Maria Elisabeth (2005), Descentralização do sistema de saúde no Brasil. Chapecó: Argos.

Liguori, Guido (2017), “Ideologia”, in Guido Liguori; Pasquale Voza (orgs.), Dicionário gramsciano. São Paulo: Boitempo Editorial, 398-402. Tradução de Ana Maria Chiarini, Diego Silveira Coelho Ferreira, Leandro de Oliveira Galastri e Silvia de Bernardinis.

Monasta, Attilio (2010), Antonio Gramsci. Recife: Fundação Joaquim Nabuco/Editora Massangana. Tradução de Paolo Nosella.

Paim, Jairnilson Silva (2008), Reforma sanitária brasileira: contribuição para a compreensão e crítica. Salvador/Rio de Janeiro: Editora da UFBA/Editora Fiocruz.

Paim, Jairnilson Silva (2009), O que é o SUS? Rio de Janeiro: Editora Fiocruz.

Santos, Jordana Souza (2009), "Gramsci e o papel dos intelectuais nos movimentos sociais”, Revista Espaço Acadêmico, 9(102), 147-153. Consultado a 10.04.2021, em http://periodicos.uem.br/ojs/index.php/EspacoAcademico/article/view/7128.

Simionatto, Ivete (1998), "O social e o político no pensamento de Gramsci”, in Alberto Aggio (org.), Gramsci: a vitalidade de um pensamento. São Paulo: Fundação da Editora da UNESP, 37-64. 
Vianna, Lucila Amaral Carneiro (2005), "Determinantes Sociais de Saúde: processo saúde doença”. Consultado a 23.09.2021, em http://www.unasus.unifesp.br/ biblioteca_virtual/pab/7/unidades_conteudos/unidade05/unidade05.pdf.

Violin, Tarso Cabral (2006), "A sociedade civil e o Estado ampliado, por Antonio Gramsci”, Revista Eletrônica do CEJUR, 1(1). Consultado a 23.09.2021, em http:// doi.org/10.5380/cejur.v1i1.14846.

\section{Dilermando Aparecido Borges Martins}

Mestre em Ciências Sociais Aplicadas pela Universidade Estadual de Ponta Grossa Praça Santos Andrade, n. ${ }^{\circ}$ 01, Centro, Ponta Grossa, CEP 84010-919, Paraná, Brasil Contacto: dilerborges@hotmail.com

ORCID: https://orcid.org/0000-0001-9638-9169

\section{Lislei Teresinha Preuss}

Programa de Pós-graduação em Ciências Sociais Aplicadas, Departamento de Serviço Social, Universidade Estadual de Ponta Grossa

Praça Santos Andrade, n. ${ }^{\circ}$ 01, Centro, Ponta Grossa, CEP 84010-919, Paraná, Brasil Contacto: lisleipreuss@gmail.com

ORCID: https://orcid.org/0000-0001-5786-7228

\section{Silmara Carneiro e Silva}

Programa de Pós-graduação em Ciências Sociais Aplicadas, Departamento de Serviço Social, Universidade Estadual de Ponta Grossa I Universidade Estadual de Londrina

Praça Santos Andrade, n. ${ }^{\circ} 01$, Centro, Ponta Grossa, CEP 84010-919, Paraná, Brasil

Contacto: scsilva@uepg.br

ORCID: https://orcid.org/0000-0003-3904-4329

Artigo recebido a 18.06.2020

Aprovado para publicação a 18.10.2021

https://doi.org/10.4000/rccs.12438 


\section{Analysis of the National Policy for LGBT Integral Health in Light of the Gramscian Concept of the Enlarged State}

The aim of this article is to reflect on the Policy for the Integral Health for Lesbian, Gay, Bisexual, Transvestite and Transsexual people (LGBT) in the context of health policy in Brazil and in light of Antonio Gramsci's theory of the Enlarged State, embracing the domains of the state, public policies and health. This study is conducted through bibliographic research and retains a historical and critical character. Furthermore, it describes the Gramscian concept of the Enlarged State, approaches health reform, and analyzes the institution of the National Policy for LGBT Integral Health, especially from the perspective of vulnerability in the context of health public policies. It concludes, in the light of Gramscian theory, that civil society is important to the construction of public policies for LGBT individuals.

Keywords: Brazil; health policies; LGBT; nation-state; social vulnerability.

\section{Une analyse de la Politique nationale de santé intégrale LGBT à la lumière du concept de Gramsci d'un État élargi}

Cet article a pour objectif de réfléchir sur la Politique nationale de santé intégrale pour les lesbiennes, les gays, les bisexuels, les travestis et les transsexuels (LGBT) dans le contexte des politiques publiques de santé au Brésil et à la lumière de la théorie de l'État élargi de Antonio Gramsci, couvrant les catégories État, politiques publiques et santé. Il s'agit d'une recherche bibliographique de nature historique et critique. Pour cela, on dépeint le concept gramscien de l'État élargi ; on aborde la Réforme de la santé et on analyse enfin la mise en place de la Politique nationale de santé intégrale LGBT, notamment à partir du concept de vulnérabilité dans le cadre des politiques publique de santé. Dans ce scénario, à la lumière de la théorie gramscienne, il apparaît que la société civile joue un rôle important dans la construction des politiques publiques pour la population LGBT.

Mots-clé: Brésil; État-nation; LGBT; politiques de santé; vulnérabilité sociale. 
